\title{
THE EFFECTS OF AN ACUTE REDUCTION IN BLOOD PRES- SURE BY MEANS OF DIFFERENTIAL SPINAL SYMPA- THETIC BLOCK ON THE CEREBRAL CIRCULATION OF HYPERTENSIVE PATIENTS ${ }^{1}$
}

\author{
By SEYMOUR S. KETY,2 BENTON D. KING, STEVEN M. HORVATH, WILLIAM \\ A. JEFFERS, AND JOSEPH H. HAFKENSCHIEL \\ (From the Departments of Pharmacology and Anesthesiology, the Edward B. Robinette \\ Foundation, Medical Clinic, Hospital of the University of Pennsylvania, and the \\ Harrison Department of Surgical Research, School of Medicine, \\ University of Pennsylvania, Philadelphia)
}

(Submitted for publication September 12, 1949; accepted, December 5, 1949)

Recent observations by this group on the cerebral circulation in hypertension (1) have yielded normal values for cerebral blood flow and cerebral oxygen consumption but a marked increase in cerebrovascular resistance. Since the nature of this excessive vascular tone is obscure, it was felt that studies of its behavior during an acute fall in blood pressure might be of interest. Such studies, furthermore, should be pertinent to the rationale of therapy designed to lower the blood pressure in hypertension, since a fall in blood pressure must necessarily be accompanied by a comparable embarrassment of the cerebral circulation except insofar as the high cerebrovascular tone were capable of compensatory relaxation.

Differential spinal sympathetic block, achieved by the injection of dilute procaine solution into the lumbar subarachnoid space (2), produces a considerable fall in the blood pressure of many hypertensive patients, presumably by blocking the sympathetic outflow to the abdomen and lower extremities without loss of skeletal muscle tone. This procedure, therefore, offers a means of studying the response of the cerebral circulation to a drop in blood pressure mediated by dilatation in vascular beds remote from the brain. The use of differential spinal block as a possible screening test in selecting patients for surgical sympathectomy provided an opportunity for undertaking these studies on the cerebral circulation.

1 This work was supported in part by grants to the Department of Pharmacology of the University of Pennsylvania from the Life Insurance Medical Research Fund.

2 Present adress : Department of Physiology and Pharmacology, Graduate School of Medicine, University of Pennsylvania.

\section{METHODS}

Measurements were made in 17 patients with essential hypertension who were being studied on the medical and surgical services as candidates for surgical sympathectomy. Cerebral blood flow (CBF) was determined by means of the nitrous oxide method, and with this value cerebral metabolism in terms of oxygen consumption $\left(\mathrm{CMR}_{\mathbf{2}}\right)$ and cerebrovascular resistance (CVR) were calculated as previously described $(3,4)$. Mean arterial blood pressure (MABP) was read from a damped mercury manometer attached to a needle in the femoral artery. Blood gas analyses were made in the Van Slyke-Neill manometric apparatus (5) and $\mathrm{pH}$ was measured at $37^{\circ}$ anaerobically by means of a glass electrode. Values for plasma $\mathrm{CO}_{2}$ tension were calculated by means of a nomogram (5).

A fine plastic catheter was introduced into the lumbar subarachnoid space. Needles were then placed in the superior bulb of an internal jugular vein and a femoral artery. The patients rested supine for 30 minutes after which control observations were made. Twenty cc. of procaine hydrochloride $(0.2 \%$ in physiological saline solution) were then introduced intrathecally, usually resulting in diminution of pain sensibility over the lower extremities and well into the intercostal region. This level of anesthesia was kept relatively constant by the instillation of more procaine as needed. The blood pressure usually fell promptly and sometimes markedly, then showed a tendency to remain at a level somewhat above the lowest point reached. When this stabilization had occurred a second determination of cerebral blood flow was made. In some cases the lowest point was not reached until after the period of stabilization and after the second cerebral blood flow determination. At some of these other points in the blood pressure curve, where mean pressure was significantly lower than its stabilized value, single samples of arterial and internal jugular blood were taken for measurement of oxygen and carbon dioxide contents and $\mathrm{pH}$.

\section{RESULTS}

All the data obtained are presented in Tables I and II. Following differential spinal block there 
EFFECTS OF SPINAL SYMPATHETIC BLOCK IN HYPERTENSION

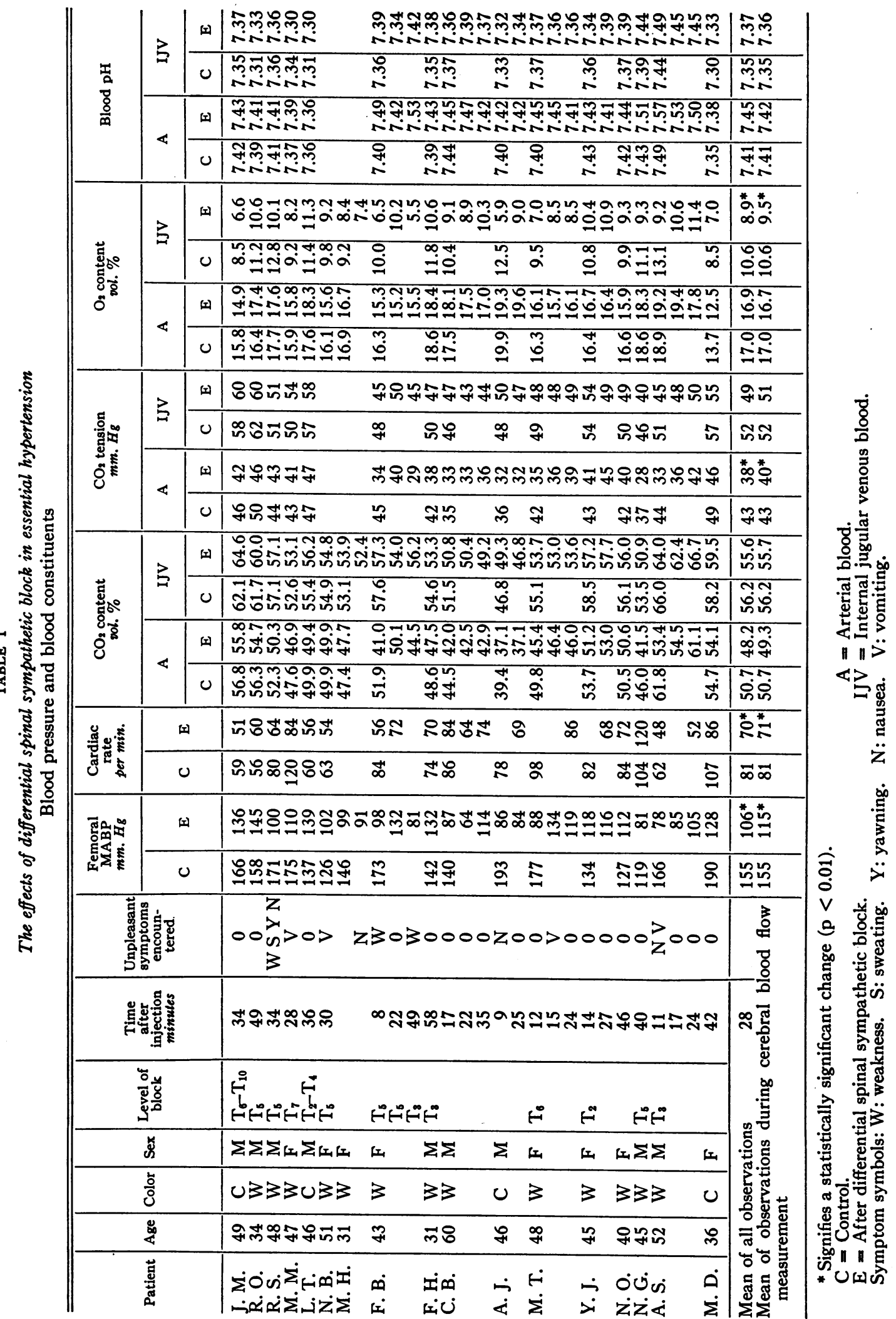


TABLE II

The effects of differential spinal sympathetic block in essential hypertension Cerebral circulation and metabolism

\begin{tabular}{|c|c|c|c|c|c|c|c|c|c|c|}
\hline \multirow{3}{*}{ Patient } & \multicolumn{2}{|c|}{$\mathrm{A}-\mathrm{V}_{\mathrm{O}_{2}}$} & \multicolumn{2}{|c|}{ CBF } & \multicolumn{2}{|c|}{$\mathrm{CMR}_{\mathrm{O}_{2}}$} & \multicolumn{2}{|c|}{$\mathbf{R Q}$} & \multicolumn{2}{|c|}{ CVR } \\
\hline & \multicolumn{2}{|c|}{ vol. \% } & \multicolumn{2}{|c|}{$c c . / 100 \mathrm{G} . / \mathrm{min}}$. & \multicolumn{2}{|c|}{ cc./100G./min. } & \multirow[b]{2}{*}{ C } & \multirow[b]{2}{*}{ E } & \multicolumn{2}{|c|}{$\frac{m m . H g}{c c_{0} / 100 G . / m i n}$} \\
\hline & C & E & C & E & C & $\mathrm{E}$ & & & C & $\mathbf{E}$ \\
\hline $\begin{array}{l}\text { J. M. } \\
\text { R. O. } \\
\text { R. S. } \\
\text { M. M. } \\
\text { L. T. } \\
\text { N. Be } \\
\text { M. H. }\end{array}$ & $\begin{array}{l}7.3 \\
5.2 \\
4.9 \\
6.7 \\
6.2 \\
6.2 \\
7.8\end{array}$ & $\begin{array}{l}8.3 \\
6.8 \\
7.5 \\
7.6 \\
7.0 \\
6.3 \\
8.3\end{array}$ & $\begin{array}{l}45 \\
52 \\
64 \\
52 \\
55 \\
44 \\
66\end{array}$ & $\begin{array}{l}35 \\
47 \\
52 \\
49 \\
53 \\
52 \\
35\end{array}$ & $\begin{array}{l}3.3 \\
2.7 \\
3.1 \\
3.5 \\
3.4 \\
2.7 \\
5.1\end{array}$ & $\begin{array}{l}2.9 \\
3.2 \\
3.9 \\
3.7 \\
3.7 \\
3.3 \\
2.9\end{array}$ & $\begin{array}{l}0.73 \\
1.04 \\
0.98 \\
0.75 \\
0.89 \\
0.79 \\
0.74\end{array}$ & $\begin{array}{l}0.91 \\
0.78 \\
0.91 \\
0.82 \\
0.97 \\
0.77 \\
0.75\end{array}$ & $\begin{array}{l}3.7 \\
3.0 \\
2.7 \\
3.4 \\
2.5 \\
2.9 \\
2.2\end{array}$ & $\begin{array}{l}3.9 \\
3.1 \\
1.9 \\
2.2 \\
2.6 \\
2.0 \\
2.8\end{array}$ \\
\hline F. B. & 6.3 & $\begin{array}{r}8.8 \\
5.0\end{array}$ & 62 & 52 & 3.9 & 2.6 & 0.91 & $\begin{array}{l}1.17 \\
0.78\end{array}$ & 2.8 & 2.5 \\
\hline $\begin{array}{l}\text { F. H. } \\
\text { C. B. }\end{array}$ & $\begin{array}{l}6.8 \\
7.1\end{array}$ & $\begin{array}{r}10.1 \\
7.6 \\
9.0 \\
8.6\end{array}$ & $\begin{array}{l}54 \\
40\end{array}$ & 39 & $\begin{array}{l}3.7 \\
2.8\end{array}$ & 3.0 & $\begin{array}{l}0.88 \\
0.99\end{array}$ & $\begin{array}{l}1.10 \\
0.77 \\
0.97 \\
0.92\end{array}$ & $\begin{array}{l}2.6 \\
3.5\end{array}$ & 3.4 \\
\hline A. J. & 7.4 & $\begin{array}{r}6.7 \\
13.4\end{array}$ & 36 & 44 & 2.7 & 2.9 & 1.00 & $\begin{array}{l}0.94 \\
0.91\end{array}$ & 5.4 & 2.6 \\
\hline M. T. & 6.8 & $\begin{array}{r}9.1 \\
7.2\end{array}$ & 46 & 20 & 3.1 & 2.8 & 0.79 & $\begin{array}{l}0.91 \\
0.91 \\
0.92\end{array}$ & 3.9 & 0.2 \\
\hline Y. J. & 5.6 & $\begin{array}{l}7.6 \\
6.3 \\
5.6\end{array}$ & 57 & 42 & 3.2 & 3.2 & 0.87 & $\begin{array}{l}1.00 \\
0.95\end{array}$ & 2.4 & 2.8 \\
\hline $\begin{array}{l}\text { N. O. } \\
\text { N. G. } \\
\text { A. S. }\end{array}$ & $\begin{array}{l}6.7 \\
7.5 \\
5.8\end{array}$ & $\begin{array}{r}3.0 \\
6.6 \\
9.0 \\
10.0 \\
8.8\end{array}$ & $\begin{array}{l}58 \\
43 \\
47\end{array}$ & $\begin{array}{l}50 \\
56 \\
31\end{array}$ & $\begin{array}{l}3.9 \\
3.2 \\
2.7\end{array}$ & $\begin{array}{l}3.1 \\
3.7 \\
2.8\end{array}$ & $\begin{array}{l}0.84 \\
1.00 \\
0.72\end{array}$ & $\begin{array}{l}0.80 \\
0.83 \\
1.04 \\
1.06 \\
0.90\end{array}$ & $\begin{array}{l}2.2 \\
2.8 \\
3.5\end{array}$ & $\begin{array}{l}2.1 \\
2.0 \\
2.6\end{array}$ \\
\hline M. D. & 5.2 & $\begin{array}{l}6.4 \\
5.5\end{array}$ & 65 & $\begin{array}{l}47 \\
60\end{array}$ & 3.4 & $\begin{array}{l}3.0 \\
3.3\end{array}$ & 0.67 & $\begin{array}{l}0.88 \\
1.00\end{array}$ & 2.9 & $\begin{array}{l}2.2 \\
2.1\end{array}$ \\
\hline Mean & 6.4 & $7.6^{*}$ & 52 & $46^{*}$ & 3.3 & 3.2 & 0.91 & 0.92 & 3.1 & $2.6^{\prime}$ \\
\hline
\end{tabular}

* Signifies a statistically significant change $(p<0.01)$.

$\mathrm{C}=$ Control.

$\mathrm{E}=$ After differential spinal sympathetic block.

was a significant fall in mean arterial blood pressure from a mean of 155 to $115 \mathrm{~mm}$. of $\mathrm{Hg}$ at the stabilized level. This does not reflect the lowest values reached which were sometimes as low as 64 $\mathrm{mm}$. Hg. A significant bradycardia accompanied the hypotension. The slight but statistically significant decrease in arterial $\mathrm{CO}_{2}$ tension reflects a mild degree of hyperpnea which was usually observed to accompany the drop in blood pressure. The internal jugular blood oxygen concentration showed a highly significant reduction from a resting value of 10.6 to $9.5 \mathrm{vol} . \%$ following differential spinal block. A comparable increase occurred in the cerebral arteriovenous oxygen difference. This decrease in oxygen saturation of cerebral venous blood may be attributed to the significant and comparable reduction in cerebral blood flow from the control value of 52 to a mean of $46 \mathrm{cc} . / 100 \mathrm{G} . / \mathrm{min}$., associated with no significant change in cerebral oxygen consumption. Since there was a $26 \%$ reduction in mean arterial blood pressure it is interesting that the fall in cerebral blood flow was only $12 \%$. This is readily explained by the fact that the cerebrovascular resistance decreased from 3.1 to 2.6 resistance units, indicating a significant relaxation of cerebral vessels during the hypotensive period.

\section{DISCUSSION}

These studies demonstrate that the high tone of cerebral vessels normally present in essential hypertension is capable of partial relaxation in response to a fall in blood pressure, thus tending to counteract the decrease in cerebral blood flow which would otherwise occur. Some questions arise as to the nature of this adjustment and why 
it is not complete. The level of the block to pin prick was never above T-2, signs of sympathetic block to the face and eyes were never noted, and skin temperature measurements showed no evidence of vasodilatation in the upper extremities. Furthermore, bilateral procaine block of the stellate ganglia has previously been shown to produce no relaxation of cerebral blood vessels in normotensive or hypertensive patients (6). It may reasonably be concluded, therefore, that interruption of sympathetic pathways to the head did not occur in the present series and in any case could not have accounted for the cerebrovascular dilatation which took place. That this decrease in resistance is a response on the part of cerebral vessels to a drop in blood pressure is further indicated by a significant correlation $(r=0.65, p<0.01)$ between these two changes. The relatively poor correlation between the decrease in cerebral blood flow and the fall in blood pressure $(\mathrm{r}=0.21, \mathrm{p}>$ 0.10) emphasizes the tendency to maintain the cerebral circulation.

It is apparent from the fact that cerebral blood flow fell significantly, that the relaxation of cerebral vessels does not compensate completely for the fall in blood pressure. Cerebral blood flow measurements were made, as noted previously, at stabilized blood pressure levels representing only a moderate decrease from the resting value. The failure of instantaneous and complete cerebrovascular compensation is more strikingly demonstrated during the relatively transitory but more profound blood pressure drops observed in many of the patients. Although complete studies could not be made at these levels the cerebral arteriovenous oxygen differences which could be obtained yielded valuable supplementary information. By rearranging the Fick formula for oxygen uptake by the brain ${ }^{3}$ we obtain : $A-V_{\mathrm{O}_{2}}=\frac{C M R_{\mathrm{O}_{2}}}{\mathrm{CBF}}$. Therefore the reciprocal of the cerebral arteriovenous oxygen difference represents a useful concept : the ratio of cerebral blood flow to metabolic demand. Thus an increase in $\mathrm{A}-\mathrm{V}_{\mathrm{O}_{2}}$ signifies a decrease in the ability of the cerebral circulation to meet the metabolic needs of the brain even though it con-

3 Since there is little storage capacity for oxygen in the small blood content of the brain and in the brain tissue itself, this principle is applicable even for relatively short time intervals. veys no information with respect to either blood flow or metabolism separately. We may then use the arteriovenous oxygen difference with this understanding as an inverse measure of the sufficiency of the cerebral circulation.

Changes in cerebral $\mathrm{A}-\mathrm{V}_{\mathbf{O}_{2}}$ are fairly well correlated with changes in mean arterial blood pressure. Coefficients of correlation and regression lines were calculated separately for changes in blood pressure less than and greater than $60 \mathrm{~mm}$. of mercury. In the former group of "moderate blood pressure reduction" there was little impairment of cerebral circulatory sufficiency ( $r=$ -0.22 , comparing well with $r=0.21$ for cerebral blood flow change). In the observations associated with a blood pressure fall greater than $60 \mathrm{~mm}$. the correlation was highly significant $(r=-0.84$, $\mathrm{p}<0.001$ ) and the slope was much steeper, indicating a marked impairment of cerebral circulatory sufficiency with sudden severe falls in blood pressure. This observation is compatible with the evidence for a limited cerebrovascular relaxation obtained from the cerebral blood flow measurements.

These observations have some pertinence to the nature of the high cerebrovascular resistance consistently found in essential hypertension. One possible explanation may be that it is compensatory and mediated by the carotid sinus or by some intrinsic homeostatic mechanism designed to confine the cerebral blood flow to normal values in the face of an increased arterial pressure arising in the extracerebral circulation. If this were the chief mechanism responsible for the high cerebrovascular tone in hypertension one should expect a release of that tone pari passu with a fall in blood pressure toward normal. Since such a relaxation does not occur acutely and completely some other component is probably present; this could well be a circulating constrictor substance which continues to act after the blood pressure has fallen.

Regardless of its nature, there is a definite but partial failure in cerebral circulatory homeostasis when the blood pressure of a hypertensive patient is caused to fall by differential spinal anesthesia. This is clearly demonstrated in Figure 1 where the change in cerebral venous oxygen content is plotted against the fall in blood pressure. ${ }^{4}$ The

4 The authors recognize that venous oxygen content is a less adequate measure of cerebral oxygen homeostasis than venous oxygen saturation or tension. Unfortunately 
CHANGE IN MEAN ARTERIAL BLOOD PRESSURE (MM.HG)

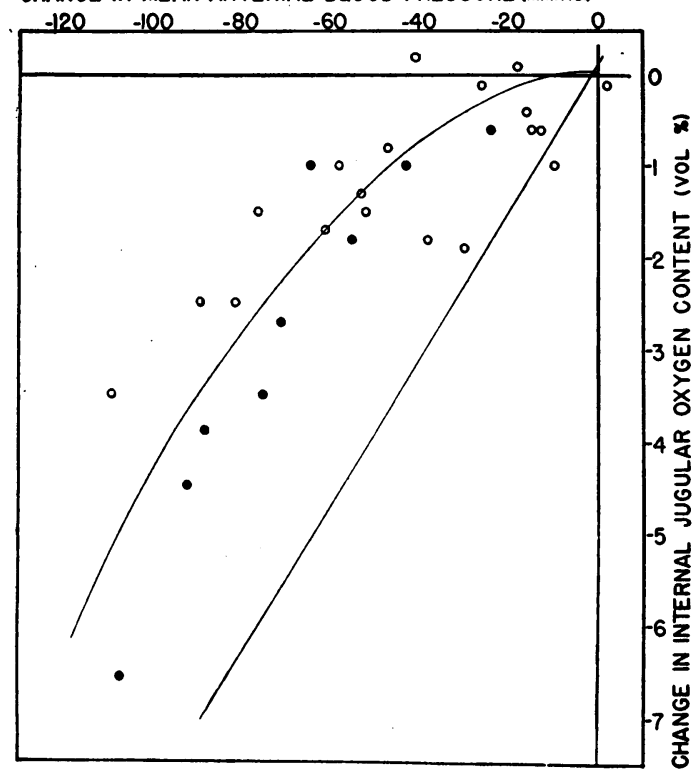

Fig. 1. Change in Internal Jugular Oxygen Content Plotted Against Change in Mean Arterial Pressure Following Differential Spinal Block

The horizontal line at zero represents perfect cerebral circulatory homeostasis, and the diagonal line complete absence of homeostasis. Closed circles denote those observations during subjective symptoms.

horizontal line signifying no change in oxygen content may be taken as representing the line of perfect homeostasis. The diagonal line is the line of regression $(r=0.95)$ of values for $\Delta V_{0_{2}}$ calculated on the assumption of complete absence of cerebral circulatory homeostasis. It is seen that the actual values obtained lie between these two lines along a parabolic curve of regression, indicating a tendency to preserve cerebral circulatory homeostasis with moderate falls in blood pressure and a progressive loss of this compensation when the hypotension becomes severe.

Those observations (Figure 1) which were associated with acute symptoms of nausea, vomiting,

blood oxygen capacity was not measured in these patients and, therefore, changes in venous oxygen saturation can be calculated only on the reasonable assumption that arterial oxygen saturation remained normal and constant throughout. This has been done and the changes in cerebral venous oxygen saturation thus calculated show a regression on change in blood pressure which is practically identical with that shown in Figure 1. The authors prefer to report those data actually measured rather than ones calculated on however reasonable an assumption. weakness or syncope are indicated by solid circles. Eight of these nine observations fall below the average curve. The mean values for cerebral venous oxygen content and calculated venous oxygen saturation and $\mathrm{pO}_{2}$ during these symptoms were 7.8 vol. $\%, 45.2 \%$, and $25.0 \mathrm{~mm}$. $\mathrm{Hg}$, figures which are significantly lower $(\mathrm{p}<0.02)$ than the means of 9.5 vol. $\%, 53.4 \%$ and $29.5 \mathrm{~mm}$. $\mathrm{Hg}$, respectively, representing observations obtained after spinal block but unassociated with such symptoms. This suggests that symptoms of nausea, vomiting, weakness, and syncope, which sometimes occur in hypertensive patients who suffer a sudden fall in blood pressure, are the result of cerebral anoxia on the basis of an inadequate cerebral circulation.

The hyperventilation and its resultant significant decrease in arterial $\mathrm{pCO}_{2}$ which accompanied the hypotension is of interest in its relation, as cause or effect, to the decrease in cerebral circulation. Since hyperventilation in itself is capable of causing considerable increase in cerebrovascular resistance and reduction in cerebral blood flow (7), it was important to examine the possibility that the hyperventilation in these patients was the prime factor preventing adequate relaxation of cerebral vessels. In this connection partial correlation analysis of the relationship between changes in cerebral venous oxygen content, blood pressure, and arterial carbon dioxide content is of value. The linear correlation coefficient between the drop in cerebral venous oxygen content $\left(\Delta \mathrm{V}_{\mathrm{O}_{2}}\right)$ and the decrease in blood pressure $(\Delta \mathrm{BP})$ for all 27 instances where these observations were made was 0.82 ( $p<0.001)$. The partial correlation between $\Delta \mathrm{V}_{\mathrm{O}_{2}}$ and $\Delta \mathrm{A}_{\mathrm{CO}_{2}}$ with the influence of $\Delta \mathrm{BP}$ removed was only $0.27(P>0.1)$ while the partial correlation between $\Delta \mathrm{V}_{\mathrm{O}_{2}}$ and $\Delta \mathrm{BP}$ with the influence of $\Delta \mathrm{A}_{\mathrm{CO}_{2}}$ removed was still quite high (0.75, p $<0.001)$. Apportionment of the total variance in $\Delta \mathrm{V}_{\mathrm{O}_{2}}$ yields substantially the same result, with $52 \%$ of $\Delta \mathrm{V}_{\mathrm{O}_{2}}$ attributable to $\Delta \mathrm{BP}$ alone, $3 \%$ due to $\Delta \mathrm{A}_{\mathrm{CO}_{2}}$ alone, $14 \%$ due to the combined effect of $\Delta \mathrm{BP}$ and $\Delta \mathrm{A}_{\mathrm{CO}_{2}}$, and $33 \%$ remaining unexplained by either or both of these factors. It is unlikely, therefore, that the hyperventilation plays any important role in restricting the cerebral circulation in these cases. An explanation which is more compatible with the statistical analysis above is that an immediate fall in blood pressure accompanied by only a limited vascular relaxation in the 
brain disturbs cerebral homeostasis with a resultant decrease in oxygen tension and a rise in carbon dioxide tension in various parts of the brain. The latter disturbance acting via the respiratory center may now effect a hyperpnea which, as a secondary homeostatic mechanism, reduces the $\mathrm{pCO}_{2}$ in the arterial blood and maintains a relatively unchanged concentration of this substance in the brain as reflected in the cerebral venous blood (Table I). The arterial oxygen content cannot be increased by this hyperpnea with the result that cerebral venous oxygen content (and therefore, presumably, cerebral oxygen tension) cannot be prevented from falling.

The time course of these changes may be of interest. The falls in blood pressure and in cerebral venous oxygen content show a correlation with time ( $r=-0.49$ and -0.32 respectively). Since the cerebral venous oxygen shows no greater tendency than the blood pressure to recover with time, there is in these data no evidence that cerebrovascular relaxation, inadequate at first, becomes more adequate in the time periods studied. Post sympathectomy studies (8), however, show that, after a reduction in blood pressure of considerably longer duration, the high cerebrovascular resistance associated with essential hypertension relaxes sufficiently to permit a normal cerebral blood flow.

These observations upon differential spinal block, where the hypotension is produced by action on vessels remote from the brain, may be contrasted with similar observations made during a drop in blood pressure produced by the parenteral injection of dihydroergocornine (9). In the latter studies no significant changes were found in cerebral blood flow or cerebral venous oxygen content despite a fall in blood pressure of comparable magnitude.

\section{SUMMARY}

1. Studies are reported of arterial and internal jugular blood gases, cerebral blood flow, oxygen consumption, and vascular resistance in patients with essential hypertension before and after a reduction in blood pressure achieved by differential spinal sympathetic block.

2. The high cerebrovascular resistance of essential hypertension is capable of partial relaxation in response to a fall in blood pressure.

3. This relaxation is not complete with the result that with severe reduction in blood pressure to normotensive levels there is a significant reduction in cerebral blood flow and evidence of cerebral anoxia.

\section{BIBLIOGRAPHY}

1. Kety, S. S., Hafkenschiel, J. H., Jeffers, W. A., Leopold, I. H., and Shenkin, H. A., The blood flow, vascular resistance and oxygen consumption of the brain in essential hypertension. J. Clin. Invest., 1948, 27, 511.

2. Sarnoff, S. J., and Arrowood, J. G., Differential spinal block. Surgery, 1946, 20, 150.

3. Kety, S. S., The quantitative determination of cerebral blood flow in man, in: Methods in Medical Research, Vol. I. Year Book Publishers, Chicago, 1948.

4. Kety, S. S., and Schmidt, C. F., The nitrous oxide method for the quantitative determination of cerebral blood flow in man: theory, procedure and normal values. J. Clin. Invest., 1948, 27, 476.

5. Peters, J. A., and Van Slyke, D. D., Quantitative Clinical Chemistry. Williams and Wilkins, Baltimore, 1931.

6. Harmel, M. H., Hafkenschiel, J. H., Austin, G. M., Crumpton, C. W., and Kety, S. S., The effect of bilateral stellate ganglion block on the cerebral circulation in normotensive and hypertensive patients. J. Clin. Invest., 1949, 28, 415.

7. Kety, S. S., and Schmidt, C. F., Effects of alterations in the arterial tensions of carbon dioxide and oxygen on cerebral blood flow and cerebral oxygen consumption of normal young men. J. Clin. Invest., 1948, 27, 484.

8. Shenkin, H. A., Hafkenschiel, J. H., and Kety, S. S., The effects of sympathectomy on the cerebral circulation of hypertensive patients. Ann. Surg., in press.

9. Hafkenschiel, J. H., Crumpton, C. W., Moyer, J. H., and Jeffers, W. A., The effects of dihydroergocornine on the cerebral circulation of patients with essential hypertension. J. Clin. Invest., 1950, 29, 408. 